nine new minor planets. Three of these were found on a plate taken by Prof. Wolf on November 20 , three others on a plate taken by Mr. Dugan on November 2I, and the remaining three were found on a plate secured by Prof. Wolf on November 21 .

Elements and Ephemeris of Comet igO2 d.-M. G. Fayet, of the Paris Observatory, has computed the following elements and ephemeris for the orbit of the new comet, from observations made on December 3, 5 and 8 :-

$$
\begin{aligned}
& \mathrm{T}=\mathrm{I}_{903} \text { March } 13^{\circ} 976 \text { M.T. Paris. }
\end{aligned}
$$

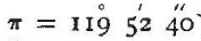

$$
\begin{aligned}
& 8=\text { II } 3939 \text { 2I } \\
& i=4353 \text { I } 1902 \\
& \log q=0.45401 \quad 9
\end{aligned}
$$

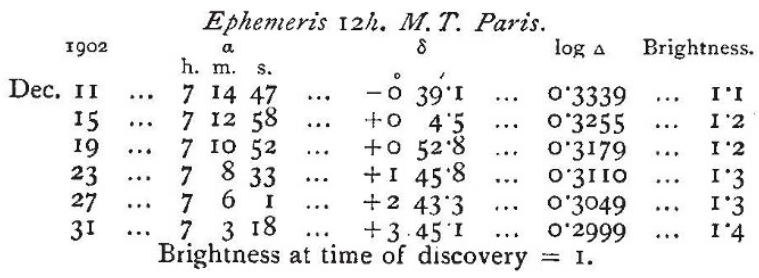

An observation was made on December rod. $13 \mathrm{~h} .37 \mathrm{~m}$. $\mathrm{o}$ at Ileidelberg by M. Courvoisier, and gave the following position for the comet : $-108^{\circ} 47^{\prime} 12^{\prime \prime},-0^{\circ} 48^{\prime} 15^{\prime \prime}$, and this gives a correction to Fayet's ephemeris of -25 . and $+0^{\prime} \cdot 6$ (Kiel Circular, No. 55).

"Companion to 'The ObServatory,' igo3."-This annual collection of elements and ephemerides, just published, contains its usual excellent list of tables and information in regard to the astronomical phenomena which will take place during the coming year.

The information concerning the various meteor showers and double stars is supplied by Messrs. Denning and Maw respectively, and M. Loewy has again contributed advance proofs from which the variable-star ephemerides have been compiled. The latter show a considerable increase in number this year.

\section{JUPITER AND HIS GREAT RED SPOT.}

$T H O U G H$ Jupiter has been unfavourably placed for European observers during the present year, his surface markings have been extremely interesting, of great variety and in plentiful numbers. The English climate, even at its best, can scarcely be said to suit astronomical work in an eminent degree, but its characteristics in 1902 have proved unusually bad, in fact, atmospheric conditions have combined with the low position of the planet to render observations difficult, and they have generally had to be pursued with definition of very inferior quality. The seeing has been recorded as "very good" on six nights only out of seventy-five, and in I90I the result was equally disappointing, for the image was really sharp and satisfactory on five nights only out of seventy-one; but in 1901 the planet was about $5^{\circ}$ lower (Dec. $23^{\circ} \mathrm{S}$.) than in 1902 (Dec. $18^{\circ} \mathrm{S}$.), and though the difference is not great, it ought to have operated strongly in favour of the present year had other circumstances been equal.

The most noteworthy incident in connection with recent studies of Jupiter is to be found in a very pronounced acceleration of motion in the great red spot. This first made itself evident in $\mathrm{J} 90 \mathrm{I}$, but it has been intensified during the past summer. For about twenty-three years, uninterruptedly, this singular marking had exhibited a constantly increasing retardation, which caused its rotation period to lengthen from about 9 h. $55 \mathrm{~m}$. $34 \mathrm{~s}$. to nearly 9 h. $55 \mathrm{~m}$. $42 \mathrm{~s}$. But in $190 \mathrm{r}$ it declined to $9 \mathrm{~h} .55 \mathrm{~m}$. $4 \mathrm{Is}$, and during the present year the rate has been about $9 \mathrm{~h} .55 \mathrm{~m}$. $39 \frac{1}{2} \mathrm{~s}$. And this increase of velocity has been contemporary with the outbreak of a large, irregular or multiple marking of a dusky hue, in the same latitude of the planet. This new object, apparently first seen in May, IgoI, has shown a rotation period of $9 \mathrm{~h} .55 \mathrm{~m} .18 \mathrm{~s}$., which corresponds with that of the south temperate current. It seems a probable conjecture that the presence of the marking just referred to may have forced the red spot along at a more rapid rate than that which it exhibited in previous years. In June, July and August of the present year, the red spot was almost surrounded by the material of the new marking, and the quicker motion of the latter may well have accelerated the movement of the former. But no certain conclusion can be arrived at, though the facts are significant and suggestive. Possibly the phenomena alluded to may have been practically coincident in date, but devoid of any physical relationship. And in this connection it will be useful to remember that the red spot has always been situated in a stream flowing along with much greater celerity than the rate of its own motion.

In September, the material of the new marking had passed to the preceding (W.) side of the red spot, and hence it was expected that the accelerated motion of the latter would cease, but the differences in motion have been comparatively slight, so that errors of observation make it unsafe to form definite conclusions. It will be advisable when the planet disappears from the evening sky in January next to collect all the transit times of the red spot recorded during the present apparition, as it may then be possible to determine with accuracy the extent of the acceleration and the variation in its rate, if any, during the summer and autumn. If a large number of observations are forthcoming, it will be desirable to group them into monthly or bi-monthly periods and ascertain the mean longitude of the spot for each of these, when the rate of its drift will be seen and the errors of individual transits practically obliterated.

\begin{tabular}{|c|c|c|c|c|c|c|c|}
\hline $\begin{array}{l}\text { Date. } \\
\text { Igoz. }\end{array}$ & & & & $\begin{array}{c}\text { G.M.T. } \\
\text { h. m. }\end{array}$ & & & ongitude \\
\hline April & 28 & $\ldots$ & $\ldots$ & $16 \mathrm{I} 4$ & $\ldots$ & $\ldots$ & $45^{\circ} \cdot 9$ \\
\hline May & 20 & $\ldots$ & $\ldots$ & I4 23 & $\ldots$ & $\ldots$ & 44.7 \\
\hline June & 20 & $\ldots$ & $\ldots$ & I4 $5^{6}$ & $\ldots$ & $\ldots$ & 448 \\
\hline & 27 & $\ldots$ & $\ldots$ & 1537 & $\ldots$ & $\ldots$ & $42 \cdot 2$ \\
\hline July & 2 & $\ldots$ & $\ldots$ & 1449 & $\ldots$ & $\ldots$ & $45 \cdot 1$ \\
\hline ", & 7 & $\cdots$ & $\ldots$ & I3 54 & $\ldots$ & $\ldots$ & 43.9 \\
\hline & 9 & $\ldots$ & $\ldots$ & 1533 & $\ldots$ & $\ldots$ & 44.5 \\
\hline Aug. & 8 & $\ldots$ & $\therefore$ & 108 & $\cdots$ & $\ldots$ & $40 \cdot 2$ \\
\hline ", & 12 & $\ldots$ & $\ldots$ & 1329 & $\ldots$ & $\ldots$ & $4 \mathrm{I} \cdot 7$ \\
\hline ," & I 5 & $\ldots$ & $\ldots$ & 1057 & $\ldots$ & $\ldots$ & $42 \cdot 5$ \\
\hline ", & 20 & $\ldots$ & $\ldots$ & IO 3 & $\ldots$ & $\ldots$ & $41 \cdot 7$ \\
\hline c" & 25 & $\ldots$ & $\ldots$ & 97 & $\ldots$ & $\ldots$ & $39^{\circ} 6$ \\
\hline Sept. & I & $\ldots$ & $\cdots$ & 950 & $\ldots$ & $\cdots$ & 38.0 \\
\hline, & 13 & $\ldots$ & $\ldots$ & 948 & $\ldots$ & $\ldots$ & $40 \cdot 3$ \\
\hline , & 18 & $\ldots$ & $\cdots$ & $856 \frac{1}{2}$ & $\ldots$ & $\ldots$ & $40 \cdot 5$ \\
\hline & 28 & $\ldots$ & $\ldots$ & 79 & $\ldots$ & $\ldots$ & 37.9 \\
\hline $\begin{array}{l}\text { Oct. } \\
\text { ", }\end{array}$ & 3 & $\ldots$ & $\ldots$ & 6 I8 & $\ldots$ & $\ldots$ & 37.9 \\
\hline ", & 10 & $\cdots$ & $\cdots$ & 79 & $\cdots$ & $\ldots$ & $40 \cdot 2$ \\
\hline ", & I 5 & $\ldots$ & $\ldots$ & 613 & $\cdots$ & $\ldots$ & $37^{\circ} \mathrm{I}$ \\
\hline & 22 & $\cdots$ & $\cdots$ & 71 & $\cdots$ & $\cdots$ & $37^{\circ} \mathrm{I}$ \\
\hline Nov. & 8 & $\ldots$ & $\ldots$ & 68 & $\ldots$ & $\ldots$ & $36 \cdot 9$ \\
\hline , & 18 & $\ldots$ & .. & $43^{1 \frac{1}{2}}$ & $\ldots$ & $\ldots$ & $39^{\circ} 4$ \\
\hline ", & 23 & $\cdots$ & $\cdots$ & 336 & $\cdots$ & $\ldots$ & $3^{6 \cdot 1}$ \\
\hline , & 25 & $\ldots$ & $\ldots$ & 520 & $\ldots$ & $\ldots$ & $39^{\circ} \mathrm{I}$ \\
\hline
\end{tabular}

At Bristol, the following estimated transits have been obtained with a Io.inch reflector and a power of 312 :-

During the present year, a number of white and dark spots have been visible on the north side of the north equatorial belt, and the mean rotation period of these has been about ten seconds less than that shown by the red spot. A new belt has lately formed on the northern side of the spots alluded to. The equatorial current of the planet has been moving, as nearly as possible, at the same rate as during I9OI, for the mean rotation of twenty-four spots is about $9 \mathrm{~h}$. 50m. 29s. There has been an abundance of slow-moving $\mathrm{N}$. and N.N. temperate markings, but these have seldom been well seen owing to the confused definition.

\section{W. F. DENNING。}

\section{SOME LIMITS IN HEAVY ELECTRICAL ENGINEERING. ${ }^{1}$}

$\mathrm{T}$ is customary for a presidential address to be a review of the development of the science with which the Institution is particularly concerned. Such a review is especially beneficial in the case of such a rapidly growing industry as electrical engineering, as the outlook changes considerably during a year. Instead of a review of the past, a dream of the future may take the form of a presidential address. This form has great

1 Abridged from the inaugural address by the president of the Institution of Electrical Engineers, Mr. James Swinburne.

$$
\text { NO. } 1729 \text {, vOL. 67] }
$$

